\title{
Enhanced Recovery After Surgery: A Better Protocol for Better Outcomes
}

\author{
Ahmed Ahmed, MBBCh, MSc*1, Alaa Ali M. Elzohry, MD ${ }^{2}$ \\ ${ }^{1}$ Postdoctoral Fellow Anaesthesiology, The Ohio State University Wexner Medical Center, Columbus, USA. \\ ${ }^{2}$ Lecturer Anesthesia, ICU and pain management, South Egypt Cancer Institute, Assiut University, Egypt. \\ ahmed.ahmed@osumc.edu \\ *Corresponding Author: Postdoctoral Fellow Anaesthesiology, The Ohio State University Wexner Medical Center, \\ Columbus, Ohio, USA.
}

\section{Abstract}

Background: Enhanced Recovery After Surgery (ERAS) is a multimodal perioperative management approach that provides better outcomes for less expense. ERAS has been introduced to the practice to improve patients perioperative performance and solve barriers to early discharge. ERAS protocol is formed of multiple components, implemented together in a synergistic way to maximize patients' improvement and cost savings. Currently, many surgeries can be managed with ERAS protocol. However, the diversity of surgical procedures makes it difficult to manage every surgical specialty with a single uniform ERAS protocol. Multiplicity and complexity of ERAS components are considered main barriers to significant adherence and successful adoption of the protocol in the clinical practice, rendering full protocol implementation a serious challenge.

Objectives: This article is aiming to review the current ERAS components and its contribution to perioperative outcomes in the clinical practice.

Contents: This article contains review on significance, guidelines and recommendations of current ERAS components in the perioperative pathway.

Conclusion: ERAS is formed of multiple components that need to be refined to provide a procedure-specific ERAS protocol rather than a single uniform protocol for different surgical specialties. ERAS is a multidisciplinary protocol that needs enormous collaborative efforts from patients, nurses, physicians, and administrative staff involved in the perioperative care of surgical patients to ensure full and correct implementation of ERAS protocol.

Keywords: Enhanced Recovery; Perioperative; ERAS; Fast track surgery

\section{INTRODUCTION}

Offering patient's safety, satisfaction, and highquality healthcare services with reduced cost is a good reflection of the perioperative value-based care. ${ }^{(1)}$ Enhanced Recovery After Surgery (ERAS) is a multimodal perioperative management approach that provides better outcomes for less expense. ${ }^{(2)}$ ERAS has been introduced to the clinical practice to improve patients' perioperative performance and solve barriers to early discharge. Currently, many surgeries have shown quick recovery, less morbidity and postoperative outcomes improvements in patients managed with ERAS protocol. ${ }^{(3)}$ However, the wide range of surgical procedures subject to ERAS protocol, makes it difficult to manage every surgical specialty with a single uniform ERAS protocol. Moreover, multiplicity and complexity of ERAS components have been deemed main barriers to significant adherence and successful adoption of the protocol in the clinical practice, rendering full protocol implementation a serious challenge. ${ }^{(4)}$. The aim of our review is to discuss the current ERAS components and its contribution on perioperative outcomes in the clinical practice. 
Enhanced Recovery After Surgery: A Better Protocol for Better Outcomes

\section{PREOPERATIVE CoMponents}

\section{Preadmission Counseling}

There is limited evidence about the benefits of preoperative education on postoperative patient outcomes in different surgical specialties. ${ }^{(5)}$ However, stoma education preoperatively in colorectal surgery has been confirmed to be beneficial in reducing the length of stay and improving patient independence. (6) Furthermore, preoperative education allows better patient involvement in decision making with subsequent improvement in patient compliance to perioperative instructions. ${ }^{(7)}$ It also has a positive psychological impact by managing patient expectation, reducing anxiety and improving satisfaction. ${ }^{(7)}$ Despite the limited evidence for this element, multiple ERAS guidelines recommend preoperative education for its potential benefits and limited risks. ${ }^{(5,8,9}$

\section{Preadmission Nutrition And Fasting}

Overnight fasting has been discouraged by many guidelines and societies for its drawbacks. ${ }^{(10)}$ Fasting for long time converts patient body to catabolic state that adversely affects postoperative muscle strength resulting in delayed recovery. ${ }^{(11)}$ Preparing the patient preoperatively in a good fed state is essential to ensure better recovery. ${ }^{(12)}$ Reducing fasting hours to six hours for solid foods and allowing oral ingestion of clear fluids two hours before induction of anesthesia, have been proven to be safe with no risks of decreased gastric $\mathrm{pH}$, delayed gastric emptying or aspiration. ${ }^{(10)}$

Carbohydrate loading drinks have been introduced to provide preoperative nutritional optimization, less thirst, hunger and anxiety and more patient comfort. (13) Patients received carbohydrates rich drinks have shown improved outcomes and reduced length of stay when compared to fasting patients. ${ }^{(14)}$ However, no differences in postoperative outcomes have been shown when carbohydrates loading group compared with clear water or placebo groups. ${ }^{(14)}$ Recent ERAS guidelines strongly recommend short fasting time; two hours for clear liquids and six hours for solid foods, ${ }^{(5,}$ $8,9,15,16)$ and oral administration of carbohydrate rich drinks two hours before surgery. $(5,8,9,17)$

\section{Bowel Preparation}

Mechanical bowel preparation (MBP) is no longer recommended as a preparatory step for abdominal surgeries. ${ }^{(18)}$ Its undesirable consequences like dehydration and electrolyte disturbances contradict
ERAS principles and delay the return of baseline body function. ${ }^{(19)}$ Furthermore, MBP has shown no beneficial effects regarding lowering the rate of postoperative complications. ${ }^{(20)}$ However, addition of oral antibiotic preparation (OBP) to MBP in recent studies has shown an evidence of reduction of surgical site infection, incisional site infection and overall morbidity. ${ }^{(21)}$

\section{Preadmission optimization}

Prehabilitaion is defined as encouragement of physical exercise before surgery meant to improve patient performance status and functional capacity.However, current literatures have illustrated poor evidence regarding its beneficial effects on clinical outcomes. (22) The questionable benefits of prehabilitation have directed ERAS guidelines for colorectal and bariatric surgeries to weakly recommend it..$^{(9,15)}$ While some other ERAS guidelines have not mentioned it at all as a part of its recommendations. ${ }^{(5,8,16,17)}$

\section{Perioperative Components}

\section{Pain Control}

Optimum pain control is a cornerstone for enhanced recovery and early discharge. ${ }^{(23)}$ Opioid alternatives like acetaminophen, nonsteroidal anti-inflammatory drugs (NSAIDs), and cyclooxygenase-2 (COX-2) inhibitors, all are examples of analgesics that can be administered to reduce opioid consumption and control postoperative pain in surgical patients. This multimodal opioid sparing analgesia when given on scheduled rather than on demand basis, has demonstrated superior reduction of postoperative pain, less opioid consumption with subsequent decrease of opioid adverse effects. ${ }^{(24)}$

Regional anesthetic techniques are considered gold standard analgesic modality that can successfully reduce the need for systemic opioid administration resulting in enhanced recovery and better outcomes. However, these better outcomes are limited to the use of thoracic epidural analgesia (TEA) for open, but not laparoscopic surgeries. ${ }^{(25)}$ Patients undergoing laparoscopic surgery and having TEA may experience delayed discharge due to the added potential for hypotension. ${ }^{(26)}$ Therefore, TEA use is a strong recommendation by ERAS guidelines for open abdominal surgeries only. ${ }^{(15)}$ While its use for laparoscopic surgeries should be limited to patients at high risk of pulmonary complications, and patients with a great possibility of conversion to open surgery 
Enhanced Recovery After Surgery: A Better Protocol for Better Outcomes

\section{Perioperative Nausea/Vomiting}

One of the major barriers to patient comfort and early discharge is postoperative nausea and vomiting (PONV). Prophylaxis against PONV is considered a major element in ERAS pathway with a strong recommendation in several ERAS guidelines for different surgeries. ${ }^{(5,8,9,15-17)}$ However, routine use of antiemetic medications for all patients has not shown any beneficial reduction in the incidence of PONV..$^{(27)}$ On the other hand, when antiemetics administered based on risk assessment, it has demonstrated significant reduction in PONV. ${ }^{(28)}$ Therefore, ERAS guidelines discourage the routine use of antiemetics for all patients and recommend administration of antiemetics based on PONV risk assessment. ${ }^{(15)}$

Preemptive multimodal prophylaxis against PONV has been shown to be superior to monotherapy with better outcomes in high risk groups. ${ }^{(29)}$ For instance, dexamethasone at induction and ondansetron at emergence have resulted in greater efficacy than single drug use. ${ }^{(30)}$ Additionally, combination of total intravenous anesthesia (TIVA) with multiple antiemetics has been revealed superior to multimodal prophylaxis with inhaled anesthetic. ${ }^{(31)}$ Interestingly, there are data reporting effectiveness of acetaminophen in reducing PONV via decreasing pain and opioid consumption. ${ }^{(32)}$ However, this effect has been shown to be limited to the preoperative intravenous (IV) administration only, and no significant effect has been noticed when the drug was given after pain onset. ${ }^{(32)}$.

\section{Intraoperative Fluid Management}

Fluid management presents a significant challenge during major surgeries. Copious and restricted fluid administrations have both demonstrated variable outcomes in major bowel surgery, suggesting that the ideal regimen may have to be tailored to each individual patient. Therefore, goal directed fluid therapy (GDFT) has been preferred in high risk patient undergoing major surgery with major fluid shift. It has been revealed to diminish post operative morbidity and decrease the length of stay. ${ }^{(33)}$ However, GDFT effects have been offset when compared with more wise fluid therapy in the setting of ERAS. ${ }^{(34)}$

During periods of hemodynamic instability due to neuraxial blockade, euvolemia should be confirmed first and any hypotension in normovolemic patients should be managed with vasopressors. ${ }^{(15)}$ A low dose vasopressor has been proven to restore organ perfusion better than fluid administration in such cases. $^{(35)}$

\section{Surgical Approach}

\section{Minimal invasiveness}

Reducing invasiveness of surgical approach using laparoscopic and robotic surgeries ensures reduction of surgical stress response. Minimally invasive approach has been illustrated to cause significant postoperative outcome improvement. ${ }^{(36)}$ When compared with open surgery, laparoscopy has shown superior short-term outcomes in the form of better postoperative pain control, earlier mobilization, rapid restoring of gut motility, with shorter length of stay. ${ }^{(37)}$ On the other hand, major concerns have been expressed about increased costs and tumor recurrence due to incomplete removal of the growth during laparoscopy use. However, several studies on laparoscopic surgeries have shown no differences in terms of complete removal of the mass, securing safety margins and recurrence rates when compared with open surgeries. ${ }^{(38)}$ Moreover, high costs associated with laparoscopy use have been offset by the savings from the lower postoperative morbidity and shorter length of hospitalization. ${ }^{(39)}$ Therefore, ERAS guidelines for different abdominal surgeries strongly recommend the minimally invasive approach whenever possible.

\section{Nasogastric Tube and Abdominal Drains}

Routine use of nasogastric tube (NGT) in abdominal surgeries has been discouraged for its questionable benefits and potential harms. ${ }^{(9,15-17)}$ Nasogastric decompression has been shown non-significant in reducing the incidence of wound dehiscence and anastomotic leaks. ${ }^{(40)}$ Patients who did not receive NGT experienced same outcomes as patients who received NGT. ${ }^{(41)}$ Moreover, NGT insertion has been linked to delayed initiation of oral intake and increased incidence of pulmonary and nasopharyngeal infections. ${ }^{(41)}$ ERAS guidelines for different abdominal surgeries recommend avoidance of routine use of NGT and suggest its selective use for patients with refractory ileus not responding to conservative management..$^{(9,15-17)}$

In the same way, routine use of intra-abdominal drains has been revealed nonbeneficial. Its routine use has been shown to be non-significant enough to demonstrate any reduction in postoperative 
complications. ${ }^{(42)}$ Instead, abdominal drains have been associated with development of more complications like fistulas and cutaneous ulceration. ERAS guidelines recommend the selective use and, when deemed possible, early removal of abdominal drains. ${ }^{(9,15)}$

\section{Postoperative Components}

\section{Mobilization}

Early mobilization has been revealed to be one of the independent predictors of successful ERAS implementation. ${ }^{(43)}$ It allows avoidance of prolonged bed rest and its adverse sequelae resulting in reduced morbidity and improved postoperative outcomes. ${ }^{(44)}$ Postoperative outcomes improvement facilitates enhanced recovery, shorter length of stay and early discharge. However, data available has shown different definitions for early mobilization with no specific strategy has been described.(15) Most of the ERAS guidelines recommend enforced early mobilization within the first 24 hours after surgery without any specification of duration, intensity, target or frequency of mobilization. ${ }^{(5,8,15)}$

\section{Illeus prevention}

Postoperative ileus is a major cause of prolonged hospitalization, patient discomfort and financial load. Prevention of postoperative ileus and promotion of bowel motility is one of the main goals of ERAS practices in different abdominal surgeries. ${ }^{(15)}$ Early postoperative feeding has been demonstrated to facilitate early return of bowel function, shorter hospital stay and faster discharge. ${ }^{(45)}$ Early offering of regular diet after surgery has shown no differences in terms of vomiting rate, need for NGT or increased complications rate. ${ }^{(46)}$ Different ERAS guidelines for colorectal surgery recommend early feeding postoperatively as soon as possible.(15)

Additionally, several studies have revealed that chewing sugar free gums may facilitate early restoring of gut mobility. ${ }^{(47)}$ Despite the poor quality of these studies, American and French ERAS guidelines for colorectal surgery recommends chewing gums for its limited risk and potential benefits. ${ }^{(15)}$

\section{Postoperative fluid management}

IV fluid should be stopped as early as possible and oral administration of clear fluid should be encouraged. Daily weight monitoring allows checking for any excess fluid administration. In hypotensive patient due to TEA, fluid responsiveness should be assessed first together with reduction of TEA rates and use of vasopressor instead of fluid in normovolemic patients. $^{(35)}$

\section{Urinary catheter}

Patients with prolonged urinary catheterization has shown to have double risk of urinary tract infection (UTI) than patients with early postoperative removal of urinary catheter. ${ }^{(48)}$ This UTI requires more care with prolonged hospitalization and increased costs. In addition, No difference in retention rates has been observed in TEA with early or late catheter removal. ${ }^{(49)}$ Therefore, urinary catheter should be removed within the first 24 hours in colonic and upper rectal surgeries, and 48 hours in mid-rectal or lower rectal surgeries and patients at risk of retention. ${ }^{(15)}$ Selective late removal is reserved only for male patients, extensive pelvic dissection and excess fluid administration. ${ }^{(50)}$

\section{ConClusion}

ERAS is formed of multiple components that need to be refined to provide a procedure-specific ERAS protocol rather than a single uniform protocol for different surgical specialties. ERAS is a multidisciplinary protocol that needs enormous collaborative efforts from patients, nurses, physicians, and administrative staff involved in the perioperative care of surgical patients to ensure full and correct implementation of ERAS protocol.

\section{REFERENCES}

1. Porter ME. What is value in health care? N Engl J Med. 2010;363(26):2477-81.

2. Ljungqvist 0 , Thanh NX, Nelson G. ERAS-Value based surgery. J Surg Oncol. 2017.

3. Ljungqvist O, Young-Fadok T, Demartines N. The History of Enhanced Recovery After Surgery and the ERAS Society. J Laparoendosc Adv Surg Tech A. 2017.

4. Li L, Jin J, Min S, Liu D, Liu L. Compliance with the enhanced recovery after surgery protocol and prognosis after colorectal cancer surgery: A prospective cohort study. Oncotarget. 2017;8(32):53531-41.

5. Dort JC, Farwell DG, Findlay M, Huber GF, Kerr P, Shea-Budgell MA, et al. Optimal Perioperative Care in Major Head and Neck Cancer Surgery 
Enhanced Recovery After Surgery: A Better Protocol for Better Outcomes

With Free Flap Reconstruction: A Consensus Review and Recommendations From the Enhanced Recovery After Surgery Society. JAMA Otolaryngol Head Neck Surg. 2017;143(3):292303.

6. Danielsen AK, Rosenberg J. Health related quality of life may increase when patients with a stoma attend patient education--a case-control study. PLoS One. 2014;9(3):e90354.

7. Temple-Oberle C, Ayeni O, Webb C, Bettger-Hahn M, Ayeni 0, Mychailyshyn N. Shared decisionmaking: applying a person-centered approach to tailored breast reconstruction information provides high satisfaction across a variety of breast reconstruction options. J Surg Oncol. 2014;110(7):796-800.

8. Temple-Oberle C, Shea-Budgell MA, Tan M, Semple JL, Schrag C, Barreto M, et al. Consensus Review of Optimal Perioperative Care in Breast Reconstruction: Enhanced Recovery after Surgery (ERAS) Society Recommendations. Plast Reconstr Surg. 2017;139(5):1056e-71e.

9. Thorell A, MacCormick AD, Awad S, Reynolds N, Roulin D, Demartines N, et al. Guidelines for Perioperative Care in Bariatric Surgery: Enhanced Recovery After Surgery (ERAS) Society Recommendations. World J Surg. 2016;40(9):2065-83.

10. Practice Guidelines for Preoperative Fasting and the Use of Pharmacologic Agents to Reduce the Risk of Pulmonary Aspiration: Application to Healthy Patients Undergoing Elective Procedures: An Updated Report by the American Society of Anesthesiologists Task Force on Preoperative Fasting and the Use of Pharmacologic Agents to Reduce the Risk of Pulmonary Aspiration. Anesthesiology. 2017;126(3):376-93.

11. Scott MJ, Baldini G, Fearon KC, Feldheiser A, Feldman LS, Gan TJ, et al. Enhanced Recovery After Surgery (ERAS) for gastrointestinal surgery, part 1: pathophysiological considerations. Acta Anaesthesiol Scand. 2015;59(10):1212-31.

12. Awad S, Varadhan KK, Ljungqvist O, Lobo DN. A meta-analysis of randomised controlled trials on preoperative oral carbohydrate treatment in elective surgery. Clin Nutr. 2013;32(1):34-44.
13. Brady M, Kinn S, Stuart P. Preoperative fasting for adults to prevent perioperative complications. Cochrane Database Syst Rev. 2003(4):CD004423.

14. Amer MA, Smith MD, Herbison GP, Plank LD, McCall JL. Network meta-analysis of the effect of preoperative carbohydrate loading on recovery after elective surgery. Br J Surg. 2017;104(3):18797.

15. Carmichael JC, Keller DS, Baldini G, Bordeianou L, Weiss E, Lee L, et al. Clinical Practice Guidelines for Enhanced Recovery After Colon and Rectal Surgery From the American Society of Colon and Rectal Surgeons and Society of American Gastrointestinal and Endoscopic Surgeons. Dis Colon Rectum. 2017;60(8):761-84.

16. Melloul E, Hubner M, Scott M, Snowden C, Prentis J, Dejong $\mathrm{CH}$, et al. Guidelines for Perioperative Care for Liver Surgery: Enhanced Recovery After Surgery (ERAS) Society Recommendations. World J Surg. 2016;40(10):2425-40.

17. Nelson G, Altman AD, Nick A, Meyer LA, Ramirez PT, Achtari C, et al. Guidelines for pre- and intraoperative care in gynecologic/oncology surgery: Enhanced Recovery After Surgery (ERAS(R)) Society recommendations--Part I. Gynecol Oncol. 2016;140(2):313-22.

18. Gustafsson UO, Scott MJ, Schwenk W, Demartines N, Roulin D, Francis N, et al. Guidelines for perioperative care in elective colonic surgery: Enhanced Recovery After Surgery (ERAS((R))) Society recommendations. World J Surg. 2013;37(2):259-84.

19. Holte K, Nielsen KG, Madsen JL, Kehlet $H$. Physiologic effects of bowel preparation. Dis Colon Rectum. 2004;47(8):1397-402.

20. Guenaga KF, Matos D, Wille-Jorgensen P. Mechanical bowel preparation for elective colorectal surgery. Cochrane Database Syst Rev. 2011(9):CD001544.

21. Moghadamyeghaneh Z, Hwang GS, Hanna MH, Carmichael JC, Mills S, Pigazzi A, et al. Surgical site infection impact of pelvic exenteration procedure. J Surg Oncol. 2015;112(5):533-7.

22. Lemanu DP, Singh PP, MacCormick AD, Arroll B, Hill AG. Effect of preoperative exercise on 
Enhanced Recovery After Surgery: A Better Protocol for Better Outcomes

cardiorespiratory function and recovery after surgery: a systematic review. World J Surg. 2013;37(4):711-20.

23. McEvoy MD, Scott MJ, Gordon DB, Grant SA, Thacker JKM, Wu CL, et al. American Society for Enhanced Recovery (ASER) and Perioperative Quality Initiative (POQI) joint consensus statement on optimal analgesia within an enhanced recovery pathway for colorectal surgery: part 1-from the preoperative period to PACU. Perioper Med (Lond). 2017;6:8.

24. Khoo CK, Vickery CJ, Forsyth N, Vinall NS, EyreBrook IA. A prospective randomized controlled trial of multimodal perioperative management protocol in patients undergoing elective colorectal resection for cancer. Ann Surg. 2007;245(6):867-72.

25. Borzellino G, Francis NK, Chapuis O, Krastinova E, Dyevre V, Genna M. Role of Epidural Analgesia within an ERAS Program after Laparoscopic Colorectal Surgery: A Review and Meta-Analysis of Randomised Controlled Studies. Surg Res Pract. 2016;2016:7543684.

26. Halabi WJ, Kang CY, Nguyen VQ, Carmichael JC, Mills S, Stamos MJ, et al. Epidural analgesia in laparoscopic colorectal surgery: a nationwide analysis of use and outcomes. JAMA Surg. 2014;149(2):130-6.

27. Kappen $\mathrm{TH}$, Vergouwe $\mathrm{Y}$, van Wolfswinkel L, Kalkman CJ, Moons KG, van Klei WA. Impact of adding therapeutic recommendations to risk assessments from a prediction model for postoperative nausea and vomiting. Br J Anaesth. 2015;114(2):252-60.

28. Kolanek B, Svartz L, Robin F, Boutin F, Beylacq L, Lasserre A, et al. Management program decreases postoperative nausea and vomiting in high-risk and in general surgical patients: a quality improvement cycle. Minerva Anestesiol. 2014;80(3):337-46.

29. White PF, O'Hara JF, Roberson CR, Wender RH, Candiotti KA, Group P-OS. The impact of current antiemetic practices on patient outcomes: a prospective study on high-risk patients. Anesth Analg. 2008;107(2):452-8.
30. Kooij FO, Vos N, Siebenga P, Klok T, Hollmann MW, Kal JE. Automated reminders decrease postoperative nausea and vomiting incidence in a general surgical population. Br J Anaesth. 2012;108(6):961-5.

31. 31. Habib AS, White WD, Eubanks S, Pappas TN, Gan TJ. A randomized comparison of a multimodal management strategy versus combination antiemetics for the prevention of postoperative nausea and vomiting. Anesth Analg. 2004;99(1):77-81.

32. 32. Apfel CC, Turan A, Souza K, Pergolizzi J, Hornuss $C$. Intravenous acetaminophen reduces postoperative nausea and vomiting: a systematic reviewand meta-analysis. Pain.2013;154(5):67789.

33. 33. Benes J, Giglio M, Brienza N, Michard F. The effects of goal-directed fluid therapy based on dynamic parameters on post-surgical outcome: a meta-analysis of randomized controlled trials. Crit Care. 2014;18(5):584.

34. 34. Gomez-Izquierdo JC, Trainito A, Mirzakandov D, Stein BL, Liberman S, Charlebois P, et al. Goaldirected Fluid Therapy Does Not Reduce Primary Postoperative Ileus after Elective Laparoscopic Colorectal Surgery: A Randomized Controlled Trial. Anesthesiology. 2017;127(1):36-49.

35. Gould TH, Grace K, Thorne G, Thomas M. Effect of thoracic epidural anaesthesia on colonic blood flow. Br J Anaesth. 2002;89(3):446-51.

36. Braga M, Frasson M, Zuliani W, Vignali A, Pecorelli N, Di Carlo V. Randomized clinical trial of laparoscopic versus open left colonic resection. Br J Surg. 2010;97(8):1180-6.

37. Hewett PJ, Allardyce RA, Bagshaw PF, Frampton CM, Frizelle FA, Rieger NA, et al. Short-term outcomes of the Australasian randomized clinical study comparing laparoscopic and conventional open surgical treatments for colon cancer: the ALCCaS trial. Ann Surg. 2008;248(5):728-38.

38. Bonjer HJ, Deijen CL, Haglind E, Group CIS. A Randomized Trial of Laparoscopic versus Open Surgery for Rectal Cancer. N Engl J Med. 2015;373(2):194.

39. Vaid S, Tucker J, Bell T, Grim R, Ahuja V. Cost analysis of laparoscopic versus open colectomy 
Enhanced Recovery After Surgery: A Better Protocol for Better Outcomes

in patients with colon cancer: results from a large nationwide population database. Am Surg. 2012;78(6):635-41.

40. Cheatham ML, Chapman WC, Key SP, Sawyers JL. A meta-analysis of selective versus routine nasogastric decompression after elective laparotomy. Ann Surg. 1995;221(5):469-76; discussion 76-8.

41. Lei WZ, Zhao GP, Cheng Z, Li K, Zhou ZG. Gastrointestinal decompression after excision and anastomosis of lower digestive tract. World J Gastroenterol. 2004;10(13):1998-2001.

42. Brown SR, Seow-Choen F, Eu KW, Heah SM, Tang CL. A prospective randomised study of drains in infra-peritoneal rectal anastomoses. Techniques in coloproctology. 2001;5(2):89-92.

43. Vlug MS, Bartels SA, Wind J, Ubbink DT, Hollmann MW, Bemelman WA, et al. Which fast track elements predictearly recovery after colon cancer surgery? Colorectal Dis. 2012;14(8):1001-8.

44. 44. Blom RL, van Heijl $M$, Bemelman WA, Hollmann MW, Klinkenbijl JH, Busch OR, et al. Initial experiences of an enhanced recovery protocol in esophageal surgery. World J Surg. 2013;37(10):2372-8.
45. Fujii T, Morita H, Sutoh T, Yajima R, Yamaguchi S, Tsutsumi S, et al. Benefit of oral feeding as early as one day after elective surgery for colorectal cancer: oral feeding on first versus second postoperative day. Int Surg. 2014;99(3):211-5.

46. Reissman $\mathrm{P}$, Teoh TA, Cohen SM, Weiss EG, Nogueras JJ, Wexner SD. Is early oral feeding safe after elective colorectal surgery? A prospective randomized trial. Ann Surg. 1995;222(1):73-7.

47. Ho YM, Smith SR, Pockney P, Lim P, Attia J. A metaanalysis on the effect of sham feeding following colectomy: should gum chewing be included in enhanced recovery after surgery protocols? Dis Colon Rectum. 2014;57(1):115-26.

48. Wald HL, Ma A, Bratzler DW, Kramer AM. Indwelling urinary catheter use in the postoperative period: analysis of the national surgical infection prevention project data. Arch Surg. 2008;143(6):551-7.

49. Zaouter C, Kaneva P, Carli F. Less urinary tract infection by earlier removal of bladder catheter in surgical patients receiving thoracic epidural analgesia. Reg Anesth Pain Med. 2009;34(6):542-8.

50. Lee SY, Kang SB, Kim DW, Oh HK, Ihn MH. Risk factors and preventive measures for acute urinary retention after rectal cancer surgery. World J Surg. 2015;39(1):275-82.

Citation: Ahmed Ahmed, Alaa Ali M. Elzohry. Enhanced Recovery After Surgery: A Better Protocol for Better Outcomes. Archives of Anesthesiology. 2018; 1(1): 1-7.

Copyright: (C) 2018 Ahmed Ahmed, Alaa Ali M. Elzohry. This is an open access article distributed under the Creative Commons Attribution License, which permits unrestricted use, distribution, and reproduction in any medium, provided the original work is properly cited. 